\title{
Uptake of yeast (Saccharomyces boulardii) in normal and rotavirus treated intestine
}

\author{
J Cartwright-Shamoon, G R Dickson, J Dodge, K E Carr
}

\begin{abstract}
Background-There has recently been a growing interest in the use of the non-pathogenic yeast Saccharomyces boulardii, in the treatment of gastrointestinal disorders, including diarrhoea. The full effects of administration of the yeast are not fully understood.

Aims-To investigate the morphological effects of inoculated $S$ boulardii on mouse intestinal villi, both in control animals and those treated with rotavirus.

Methods-Seven day old BALB/c seronegative mice were intubated with either rotavirus (30 $\mu$ l orally) or $S$ boulardii $(1 \cdot 5$ $\mathrm{g} / \mathrm{kg}$ ) or both rotavirus and $S$ boulardii administered together. Control animals were given saline only. Animals were killed by decapitation 48 hours posttreatment. The middle region of the small intestine was studied using light microscopy and transmission and scanning electron microscopy, including backscattered electron imaging.

Results-Animals treated with rotavirus with or without $S$ boulardii developed severe diarrhoea and showed morphological villous changes such as stromal separation and increased epithelial vacuolation. Specimens treated with $S$ boulardii contained yeast particles within the mucosal tissues.

Conclusion-The administration of $S$ boulardii did not influence the changes produced by rotavirus, but yeast particles appeared to be taken up by the villous mucosa, with the predominant route apparently being uptake between adjacent epithelial cells.
\end{abstract}

(Gut 1996; 39: 204-209)

Keywords: intestine, yeast, uptake, rotavirus, mice, microscopy.

School of Biomedical Science/Anatomy J Cartwright-Shamoon G R Dickson

K E Carr

School of Clinical Medicine/Child Health $\mathrm{J}$ Dodge

The Queen's University of Belfast, Northern Ireland

Correspondence to: Professor K E Carr, School of Biomedical

Science/Anatomy, The

Science/Anatomy, The

Queen's University of

Belfast, 97 Lisburn Road,

Breland.

Accepted for publication 27 February 1996

In recent years there has been a growing interest in the use of the thermophilic nonpathogenic yeast Saccharomyces boulardii for the treatment of gastrointestinal disorders. The disposition kinetics of $S$ boulardii have been characterised in humans ${ }^{1}$ and the yeast has been shown to have no adverse side effects when given to both humans and animals. ${ }^{2}$ It has been used to treat irritable bowel syndrome associated with diarrhoea ${ }^{3}$ and used in many Western European countries in cases of acute infectious diarrhoea and other gastrointestinal disturbances associated with antibiotic use. ${ }^{45}$ The mode of action of $S$ boulardii remains to be fully established, although some workers have suggested that this yeast might suppress the growth of pathogenic bacteria and improve colonisation resistance in the gut. ${ }^{6}$

It is possible that yeast may enter human intestinal mucosa ${ }^{78}$ : this suggests that yeast entry may be similar to particle uptake and translocation. The terms uptake and translocation are commonly used to describe the movement across the mucosa and beyond. In general, this describes the phenomenon previously described as persorption ${ }^{9} 10$ applied particularly to particles in the micron range and possibly involving a paracellular mechanism. The extent, timescale, and limiting factors of this process have been reviewed. ${ }^{11-13}$ The types of particles that have been studied include latex, starch, carbon, and other inorganic substances, which have been detected in the tissues of the gastrointestinal tract and in secondary organs, such as mesenteric lymph nodes, liver, and spleen. The relevance of this work to our study is found in the descriptions of the uptake of bacteria and in comments on the clinical significance of the process. ${ }^{1415}$ This paper expands on a previous short description of $S$ boulardii uptake and translocation ${ }^{16}$ and describes the sites involved in this process in the villous mucosa. It also describes the morphological effect of $S$ boulardii treatment on the small intestine of mice infected with rotavirus with respect to its possible antidiarrhoeal role.

\section{Methods}

Animals

BALB/c seronegative pathogen free (SPF) mice (ICN Biochemical) were paired together, in positive isolators, for breeding purposes and fed $\gamma$ irradiated rodent food. For each experiment, five to six litters ( $n=4-5$ mice/litter) of 7 day old mice were raised in individual litters along with their mothers

\section{Animal groups and treatment}

The administration of $S$ boulardii yeast (strain: Endomycetes; Biocodex, Montrouge, France) to infected and control mice was carried out by means of intubation. A dose of freshly prepared suspension of the yeast was made by suspending $7.5 \mathrm{mg}$ of lyophilised $S$ boulardii in $0.5 \mathrm{ml}$ of $0.9 \%$ saline $\left(6 \times 10^{8}\right.$ viable organisms $/ \mathrm{ml}$ ) and was given every six hours for two days, eight treatments in 48 hours, while control animals were intubated and given saline only. All animal procedures were carried out by licensed staff and in accordance with Home Office regulations. 
Three experimental groups of mice $(n=3-$ 5/group) were examined. In group 1 animals were infected with rotavirus (virus group; one experiment, three animals). The Cambridge strain of EDIM rotavirus, used in all infection experiments, was stored at $-70^{\circ} \mathrm{C}$. Weanling mice were infected by oral administration of a dose of $30 \mu \mathrm{l}$ of virus suspension in buffer (1.5 $\mathrm{mM} \mathrm{CaCl} 22 \mathrm{H}_{2} \mathrm{O}$ in $0 \cdot 1 \mathrm{M}$ TRIS- $\mathrm{HCl} \mathrm{pH} 7 \cdot 2$ ) and returned to their dams. This dose contained $10^{4 \cdot 5} \mathrm{ID}_{50}$ and the infectivity of the preparation remained high through the period of this work. At this stage all infected mice were kept in a negative pressure isolator. Diarrhoea was detected visually by examination of mice on three occasions per day for the presence of faecal staining of their abdominal skin. In group 2 they were treated with the yeast alone (yeast group; two experiments, three animals each, total six), and in group 3 with both organisms (virus/yeast group; one experiment, three animals). Controls received saline only (control group; two experiments).

Tissue sampling and microscopy

Mice were killed by decapitation, group 1: 48 hours post-treatment with EDIM rotavirus, group 2: 48 hours post-treatment with $S$ boulardii, group 3: 48 hours post-treatment with virus/yeast. The controls were also killed at this point: all mice were therefore 9 days old when studied. The middle region of the small intestine was cut into small pieces (between $2-4 \mathrm{~mm}^{2}$ ) and immersed in fixative, $2.5 \%$ glutaraldehyde in $0 \cdot 1 \mathrm{M}$ phosphate buffer $\mathrm{pH}$ $7 \cdot 2^{17}$ for 24 hours. Three specimens $\left(2-3 \mathrm{~mm}^{2}\right.$ in size) from each animal were prepared for light microscopy (LM) and backscattered electron imaging (BSI). Sections for examination by transmission electron microscopy (TEM) were taken from selected blocks from each group, where LM or BSI results indicated that this would be of interest. Specimens were postfixed in $2 \% \mathrm{OsO}_{4}$ in $0 \cdot 1 \mathrm{M}$ phosphate buffer, $\mathrm{pH} 7 \cdot 2$, dehydrated sequentially in ethanol solutions (up to $100 \%$ ethanol), and finally transferred into acetone. Specimens were

Figure 1: (A) Light micrograph of the middle intestine of 9 day old mouse 48 hours post-saline treatment (control). The tall absorptive cells are closely packed and the stroma also shows a densely packed cellular arrangement. (B): Light micrograph of villus from a mouse 48 hours post-infection with rotavirus. The absorptive cells are disorganised (arrow) and the stroma shows vascular dilatation and a loose cellular arrangement (original magnification $\times 800$ ).

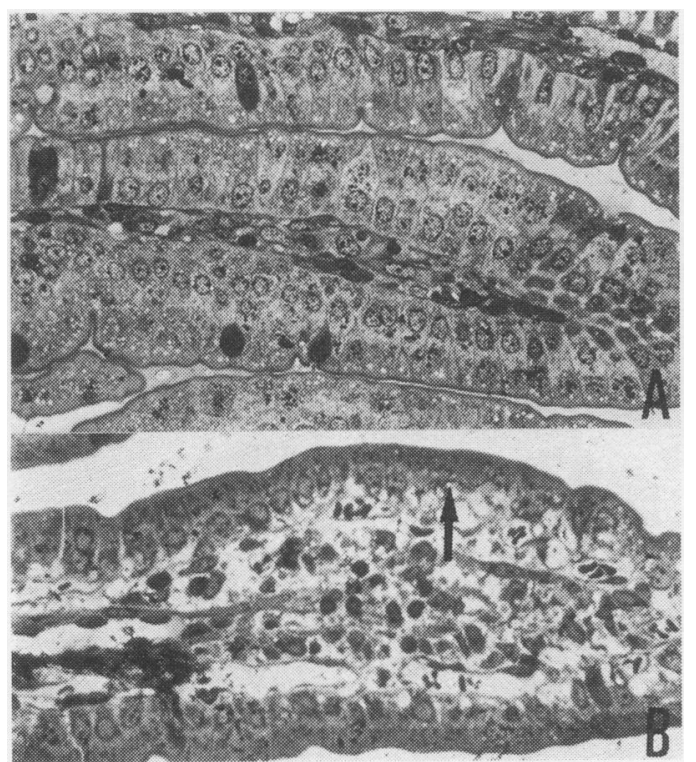

embedded in epon-araldite mixture overnight, prior to tissue embedding and resin polymerisation. For LM and BSI, semi-thin sections 1 $\mu \mathrm{m}$ thick were cut using a Reichert-Jung Ultramicrotome. Sections were either prepared for LM by mounting on slides and staining with toluidine blue, or prepared for BSI by mounting on coverslips and coating with carbon, using a BioRad E6200 Turbo coater. Ultra-thin sections $(50-70 \mathrm{~nm})$ for TEM were cut on a Reichert-Jung Ultramicrotome and stained with methanolic uranyl acetate and lead citrate. For scanning electron microscopy (SEM), three specimens (3-4 $\mathrm{mm}^{2}$ ) from each animal were fixed with $2.5 \%$ glutaraldehyde as above and dehydrated through a graded series of ethanols and amyl acetate, frozen in Freon, freeze-dried, and gold coated in a Polaron E5150 sputter coater.

For isolated yeast preparations, approximately $10 \mathrm{mg}$ of dry $S$ boulardii was placed in a plastic porous container ( $1 \mu \mathrm{m}$ pore size) and suspended in $1 \mathrm{ml}$ saline at room temperature. The container was immersed in fixative, $2 \cdot 5 \%$ glutaraldehyde in $0 \cdot 1 \mathrm{M}$ phosphate buffer $\mathrm{pH}$ $7 \cdot 2$ for 24 hours. Yeast particles for LM, BSI, and TEM were post-fixed in $2 \% \mathrm{OsO}_{4}$ in $0 \cdot 1 \mathrm{M}$ phosphate buffer, $\mathrm{pH} 7 \cdot 2$ and processed for LM, BSI, and TEM as described above. For SEM, isolated yeast particles were fixed with $2.5 \%$ glutaraldehyde, dehydrated through graded ethanols, critical point dried, and gold coated as above.

LM of sections of villi were examined using a Leitz Dialux 22 light microscope with a 35 mm camera attachment: the incidence of yeast particles per villous profile was estimated from these sections for three animals per group. Carbon coated specimens were examined using a JEOL/JSM-840A scanning electron microscope in the backscattered electron mode. ${ }^{18}$ Ultra-thin sections of villi were screened using a JEOL/JSM 100CXII transmission electron microscope. Gold coated specimens were examined with a JEOL/JSM$840 \mathrm{~A}$ scanning electron microscope. For all techniques, yeast particle dimensions, both for isolated preparations and for tissue specimens, were checked against published values.

\section{Results}

Animal health

Animals from the control group and those treated with $S$ boulardii alone (yeast group) showed no signs of diarrhoea and appeared healthy. By 24 hours, approximately half of the mice in groups 1 and 3 (virus group and virus/yeast group), showed signs of severe diarrhoea and by 48 hours all animals in both groups were affected.

\section{Morphology: effect of virus treatment}

The villi of control animals appeared normal (Fig 1A). The simple columnar epithelium covering the villus formed a continuous sheet of densely packed cells with oval nuclei located in the lower half of each cell. The core of the 
Figure 2: Scanning electron micrograph of the middle intestine of 9 day old mouse treated with $\mathrm{S}$ boulardii showing several yeast particles (arrow) adhering to the villous surface. Particle size (mean (SD)): $4 \cdot 0(0 \cdot 3) \mu \mathrm{m} \times 3 \cdot 7(0.4)$ $\mu m$ (original magnification $\times 1490)$. Insert: SEM of isolated yeast preparation. Particle size (mean (SD)) $2 \cdot 8(0 \cdot 2) \mu \mathrm{m} \times 2 \cdot 3(0 \cdot 2)$ $\mu m$ (original magnification $\times 5600)$.

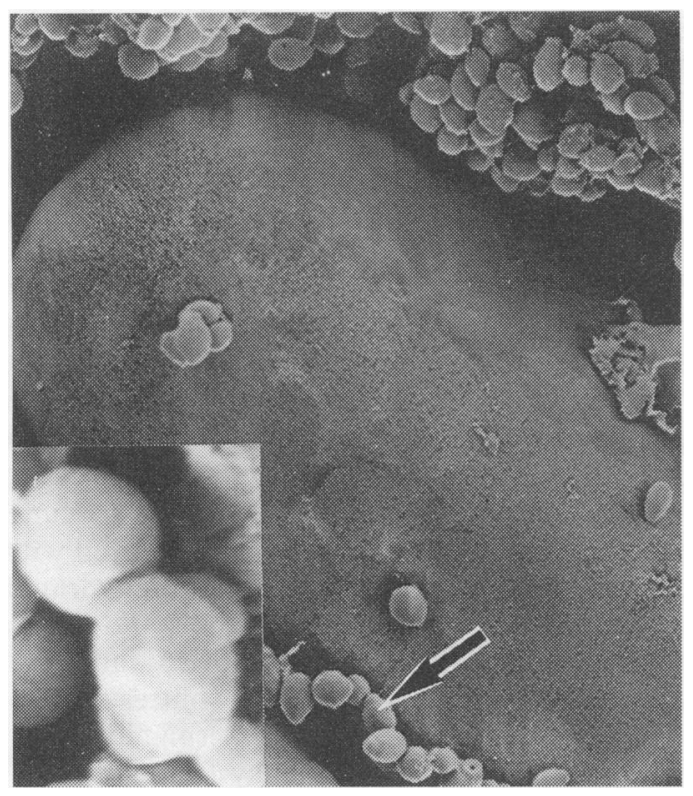

villus contained a highly cellular connective tissue (lamina propria), rich in cells of the immune system. Animals in the virus group, on the other hand, showed a disturbed villous organisation (Fig 1B). The absorptive cells of the columnar epithelium appeared disorganised with irregular nuclei. The stroma had lost its packed cellular organisation and cells were dispersed when compared with those in controls.

\section{Morphology: effect of yeast treatment}

Figures 2-6 show the effects of yeast treatment, with pictures of isolated yeast particles, seen as clusters of oval asymmetric structures, being included as inserts where appropriate. Yeast particles were seen within the lumen, adhering to the villous surface (Fig 2) and taken up into the villous compartment of intestinal samples

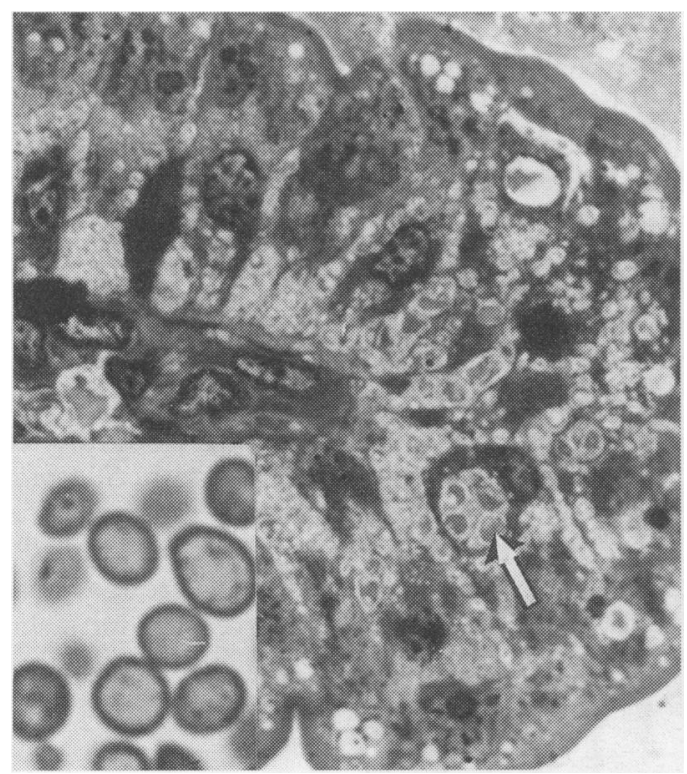

Figure 3: Light micrograph of the middle intestine of 9 day old mouse treated with $\mathrm{S}$ boulardii. A yeast-like particle (arrow) is clearly seen within the villous tip. Particle size (mean (SD)): $5.2(0.6) \mu \mathrm{m} \times 4.9(0.4) \mu \mathrm{m}$. Oil immersion (original magnification $\times 1800)$. Insert: Light micrograph of isolated yeast preparation. Particle size (mean (SD)): $1.9(0.2) \mu \mathrm{m} \times 2.6(0.25) \mu \mathrm{m}$. Oil immersion (original magnification $\times 5400$ ). from both yeast and virus/yeast groups (Figs 36 ). In the yeast group, the presence of particles (Fig 3) appeared to be the only morphological change seen in those specimens by comparison with untreated controls. In specimens from the virus/yeast group, particles were seen side by side with all the features produced by the virus alone, such as stromal separation (Fig 4). The measurements for length and width of the particles are of the same order of magnitude for all techniques, with the maximum sizes being somewhat larger $(6.6 \mu \mathrm{m} \times 6.1 \mu \mathrm{m})$ for particles within intestinal tissues than those on villous surfaces $(4.0 \mu \mathrm{m} \times 3.7 \mu \mathrm{m})$ or in isolated yeast specimens $(3.0 \mu \mathrm{m} \times 2.5 \mu \mathrm{m})$. Particles within the tissue had an internal substructure and were identified as $S$ boulardii by their similarity to the isolated yeast (Figs 3-5). In some cases they were associated with a break between epithelial cells, although serial sections were necessary to identify this and also to confirm that they were within the tissue and not located on the section as a result of sectioning artefact (Fig 6). Many particles were found between the basal parts of adjacent enterocytes, where they could be identified in TEM and BSI (Figs 5 and 6). There were also some sightings of particles apparently lying within enterocytes (Fig 6). Preliminary analysis of the incidence of yeast uptake in light microscopy specimens showed no substantial difference in the proportion of villi demonstrating uptake between the virus/yeast and yeast groups, with the extent of involvement in intraepithelial uptake being in the order of $20-50 \%$ of villi examined.

\section{Discussion}

Infection of mice with rotavirus has been widely used as an animal model for studying

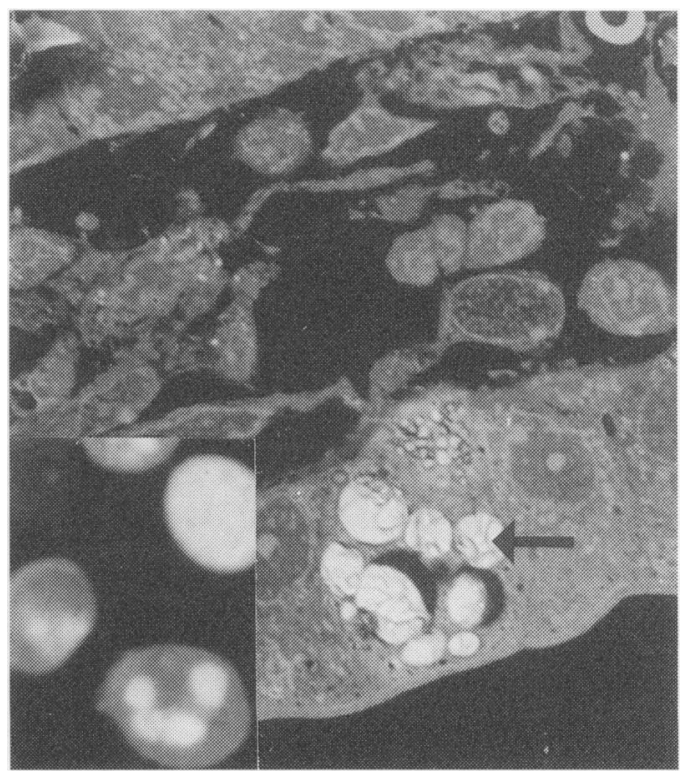

Figure 4: SEM/backscattered electron image of a resin section of the middle intestine of 9 day old mouse 48 hours post-infection with rotavirus and post-treatment with $\mathrm{S}$ boulardii. The stromal cells are widely separated. Yeast particles are clearly seen inside the villous epithelium (arrow). Particle size (mean (SD)): 6.6 (0.7) $\mu \mathrm{m} \times 6.1$ (0.65) $\mu \mathrm{m}$ (original magnification $\times 1490)$. Insert: BSI of isolated yeast preparation. Particle size (mean (SD)): $3 \cdot 2$ $(0.3) \mu m \times 2 \cdot 8(0 \cdot 35) \mu m$ (original magnification $\times 5600)$ 


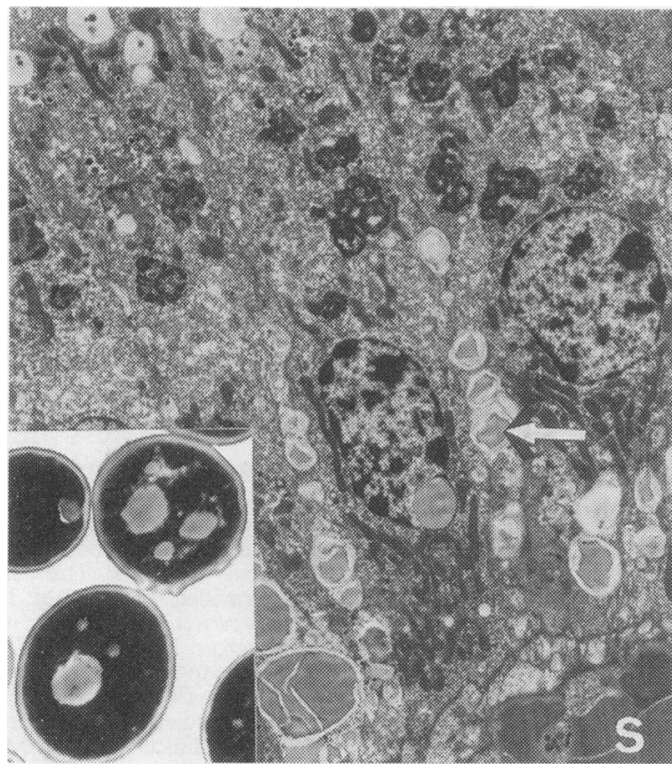

Figure 5: Transmission electron micrograph of a specimen from middle intestine of 9 day old mouse 48 hours posttreatment with $\mathrm{S}$ boulardii. Particles (arrow) are seen between the enterocytes. The fact that the level of the section is at the base of the enterocytes is shown by the proximity of a stromal blood vessel (S). Particle size (mean (SD)): $4.7(0.7) \mu m \times 3.6(0.65) \mu m$ (original magnification $\times 3600)$. Insert: TEM of isolated yeast preparation. Particle size (mean (SD)): $2.9(0.3) \mu \mathrm{m} \times 2.5(0.3) \mu \mathrm{m}$ (original magnification $\times 9000)$.

diarrhoea in the young after exposure to rotavirus, although a recent paper has commented that neonatal rats may be an excellent model. ${ }^{19}$ Our study shows that rotavirus infection produces a severe diarrhoea in neonatal mice. In morphological terms, this study confirmed that viral infection of the intestine produces several changes in villous cells, ${ }^{20}$ including vacuolated enterocyte cytoplasm and extensive oedema of the lamina propria. ${ }^{21}$ As all of the animals studied had diarrhoea, it is not possible to comment on whether the changes to villous morphology were caused by this or by other virus related changes. However, the administration of the anti-diarrhoeal $S$ boulardii to the virus treated animals had no effect on diarrhoea produced by the rotavirus, as shown by the continuing presence, despite yeast administration, of gastrointestinal signs and of viral induced morphological features.

A significant finding not previously recorded was the detection, using microscopy techniques, of yeast-like particles within the intestinal epithelium and lamina propria of treated animals, but not of controls: care has been taken in the interpretation of the images collected, to exclude inaccurate differentiation in LM between epithelial yeast particles and vacuoles and in BSI between yeast particles and either section blemishes or small lipid droplets, both seen in control as well as treated specimens. The identification of the particles as yeast is based on similarities in size and shape between the particles within the intestinal tissues and the isolated yeast. The sizes are similar to the value supplied by the manufacturer. ${ }^{22}$ The shape and substructure of the particles within the tissue are also similar to that of the isolated yeast in this study and of yeasts in general. ${ }^{23-25}$ The fact that yeast dimensions appear smaller in pure preparations in contrast with those in tissue may be related to the greater support provided to the particles by the surrounding tissue during processing, when dehydration mediated shrinkage occurs.

The identification of yeast-like structures within the villous stroma and epithelial sheet and the fact that their size is in the micrometre range makes it probable that uptake and translocation are involved. There are few published reports on uptake of $S$ boulardii. The only relevant paper ${ }^{26}$ describes $S$ boulardii as inhibiting the translocation of orally administered Candida albicans in mice. However, the report described the number of translocated Candida albicans in secondary organs such as lymph node, liver, and kidney and it is difficult to relate this to this study.

With respect to possible mechanisms involved in uptake and translocation, three possible routes are listed ${ }^{1112}$; via $M$ cells in Peyer's patches, by transcellular passage through epithelial cells or paracellularly between them. All of these routes could be relevant to this study. Although much has been made of the importance of Peyer's patch dome $M$ cells, there have also been comments that Peyer's patch villi and non-Peyer's patch mucosa are important ${ }^{27-29}$ : this study certainly shows yeast within the villous compartment, but no comment can be made on the possible involvement of $M$ cells, because the specimens did not include Peyer's patches.

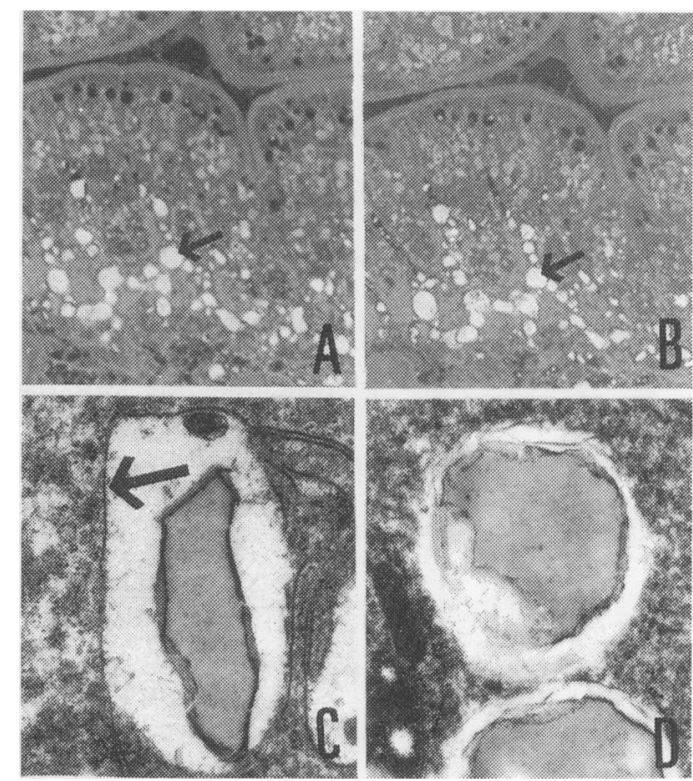

Figure 6: (A) SEM/backscattered electron image of a resin section of the middle intestine of 9 day old mouse 48 hours post-treatment with $\mathrm{S}$ boulardii, showing several yeast particles (arrow): most are between the basal parts of adjacent enterocytes (original magnification $\times 700$ ).

(B) SEM/backscattered electron image of corresponding particles, which are therefore within the tissue (original magnification $\times 700$ ). (C) Detail of a yeast particle from an area similar to that illustrated in Fig 5, showing the relation between the particle and the cell membranes (arrow) of the cells between which the particle is sitting (original magnification $\times 29000$ ). (D) Detail of particles and surrounding enterocyte cytoplasm. The lack of enterocyte cell membrane around the particles suggests that they are sitting within one of these cells, rather than in the intercellular space between two adjacent cells (original magnification $\times 15$ 000). 
There is little difficulty in proving the presence, in yeast treated samples, of particles between cells, with the cellular membranes and intercellular spaces clearly visible. Some particles are also seen in an apparently intracellular position, with no surrounding membrane: further work is needed with sampling at several time points after administration of yeast and with extensive serial sectioning for TEM to prove conclusively that these particles are being taken up through the cells and are not extracellular, with image interpretation affected by a plane of section effect. The data so far available, however, show that particles seem to be more common between the cells than within them, indicating that the paracellular pathway may be more important than the transcellular route, with the particles sometimes lining up as though delineating a favoured method of entry between cells. Several villi also displayed particles in association with breaks in the epithelial sheet. This could identify the original route of entry, but does not prove conclusively that the break occurred before the specimen was collected: such breaks might have been produced artefactually at places where the tissue was stressed by the presence of a row of particles between the cells. Whatever the extent of the break between neighbouring epithelial cells, any movement of particles paracellularly could have as a rate limiting factor the physiological regulation of enterocyte tight junctions, although the role of the junctional complex region in uptake and translocation is still unclear. Uptake may, therefore, be possible at these sites, which in other conditions act as protective barriers. ${ }^{30}$

Further studies using yeast may provide information on the exact uptake mechanism, as it is obvious that this model allows a thorough examination of the structural features associated with particle movement. Particular consideration might be given to the importance of the level of maturity or aging, because this is known to affect uptake and translocation, although published work on this subject is confusing. On one hand, there are reports of pre-weaning rats having greater uptake and translocation than post-weaning rats, possibly linked to variations in stomach emptying, ileal transit rate, and increase in gut length ${ }^{31}$ and also to physiological differences in immature enterocyte function. On the other hand, a comparison between young and aged mice showed more particles in aged Peyer's patches, but fewer in lung. ${ }^{32}$ This unexpected finding was linked to variations in transit time and particle clearance. This study cannot resolve these differences, but can confirm that the immature mice used were certainly able to take up substantial quantities of yeast. Although this study did not have as a prime objective a quantitative study of the effect of EDIM rotavirus on yeast SB uptake and translocation, the preliminary data presented here indicate that the process is not substantially affected by virus treatment. This may imply that uptake involves parts of the villus that are not adversely affected by the presence of abnormalities related to the rotavirus infection.
That further work is necessary is underlined by the possible clinical relevance ${ }^{15}$ of yeast mediated particle uptake and translocation. The potential applications of the process include vaccine release, ${ }^{33}$ oral immunisation, ${ }^{34}$ drug delivery ${ }^{1135}$ or targeted treatment of inflammation. ${ }^{14}$ Any particulate substance used regularly for human treatment should be thoroughly investigated to explore the extent to which translocation occurs, to define what, if any, are the effects on the tissues involved, and how the process might be changed by the presence of an underlying pathology.

This work was supported by research grants from Biocodex International and the Faculty of Medicine, The Queen's University of Belfast. The Cambridge strain of EDIM rotavirus was provided courtesy of $\mathrm{Dr} \mathrm{TH}$ Flewett of the WHO Collaborative Centre for Research on Rotavirus, East Birmingham Hospital, UK. The authors owe a special debt of gratitude to $\mathrm{Dr} J$ Stephen, Department of Microbiology, University of Birmingham for providing the rotavirus and for his helpful discussion. We are indebted to Professor D Simpson, School of Clinical Medicine/Microbiology and Immunology, The School of Clinical Medicine/Microbiology and Immunology, The Queen's University of Belfast and to Mr T Connors, Veterinary facilitating the use of animal isolators. We would like to thank Mr P Larkin and Mr C Ferris for skilful technical assistance.

1 Blehaut H, Massot J, Elmer GW, Levy RH. Disposition kinetics of Saccharomyces boulardii in man and rat. Biopharm Drug Dispos 1989; 10: 353-64.

2 Toothaker RD, Elmer GW. Prevention of Clindamycin induced mortality in hamsters by Saccharomyces boulardii. Antimicrob Agents Chemother 1984; 26: 552-6.

3 Maupus JL, Champemont P, Delforge M. Treatment of rritable bowel syndrome. Double-blind trial of UltraLevure. Medicine Chirurgie Digestive 1983; 12: A1.

4 Buts JP, Bernasconi P, Van Craynest MP, Maldague P, de Meyer R. Response of human and rat small intestinal mucosa to oral administration of Saccharomyces boulardii. Pediatric Res 1986; 20: 192-6.

5 Vidon N, Huchet B, Rambaud JC. Influence de Saccharomyces boulardii sur la secretion jejunale induite chez le rat par la toxine cholerique. Gastroenterol Clin Biol 1986; 10: 13-6.

6 Elmer GW, McFarland LV. Suppression by Saccharomyces Boulardii of toxigenic Clostridium difficile overgrowth after Vancomycin treatment in hamsters. Antimicrob Agents Chemother 1987; 31: 129-31.

7 Pappu-Katikaneni LD, Roa KPP, Banister E. Gastrointestinal colonisation with yeast species and candida septicemia in very low birth weight infants. Mycoses 1990 33: 20-3.

8 Sedman PC, Macfie J, Sagar P, Mitchell CJ, May J, Mancey-Jones B, et al. The prevalence of gut translocation in humans. Gastroenterology 1994; 107: 643-9.

9 Volkheimer G, Schulz FH, Hurich I, Straugh S, Beuthin K, Wendlandt H. Persorption of particles. Digestion 1968; 1: 78-80.

10 Volkheimer G, Schulz FH, Lindenau A, Beitz U. Persorption of metallic iron particles. Gut 1969; 10: 32-3.

11 O'Hagan DT. Intestinal translocation of particulates implications for drug and antigen delivery. Adv Drug Deliv Rev 1990; 5: 265-83.

12 Florence AT, Jani PU. In: Rolland A, ed. Particulate delivery: the challenge of the oral route. Pharmaceutical particulate carriers: therapeutic applications. New York: Marcel Dekker, 1993: 65-107.

13 Kreuter J. Peroral administration of nanoparticles. Adv Drug Deliv Rev 1991; 7: 71-86.

14 Deitch EA. Bacterial translocation: the influence of dietary variables. Gut 1994; 35 (suppl 1): S23-7.

15 Van Leeuwen PAM, Boermeester MA, Houdijk APJ, Ferwerda CC, Cuesta MA, Meyer S, et al. Clinical significance of translocation. Gut 1994; 35 (suppl 1): S28-34

16 Cartwright-Shamoon J, Dickson GR, Dodge J, Carr KE Morphological aspects of particle translocation in vivo following ingestion of the yeast Saccharomyces boulardii. 7 Drug Targeting 1995; 3: 61-3.

17 Glauert AM. Fixation, dehydration and embedding of biological specimens. In: Glauert AM, ed. Practical methods in electron microscopy. Vol 3. Amsterdam: North-Holland, 1974 .

18 Becker RP, Sogard M. Visualisation of subsurface structures in cells and tissues by backscattered electron structures in cells and tissues by backscattered e
imaging. Scanning Elect Microsc 1979; II: 835-70.

19 Salim AF, Philips AD, Walker-Smith JA, Farthing MJG Sequential changes in small intestinal structure and function during rotavirus infection in neonatal rats. Gut 1995 36: $231-8$.

20 Adams WR, Kraft LM. Electron microscopic study of the intestinal epithelium of mice infected with an agent of epizootic diarrhoea of infant mice (EDIM virus). Am $\mathcal{F}$ Pathol 1967; 51: 39-60.

21 Osborne MP, Haddon SJ, Spencer AJ, Collins J, Starkey WG, Wallis TS, et al. An electron microscopic investigation of time-related changes in the intestine of neonatal 
mice infected with murine rotavirus. $\mathcal{F}$ Pediat Gastroenterol Nutr 1988; 7: 236-48.

22 Biocodex International. Saccharomyces Boulardii Manual. Montrouge: Biocodex International Publication, 1991.

23 Skinner FA, Passmore SM, Davenport RR. Biology and activities of yeasts. London: Academic Press, 1980.

24 Suzuki CK, Suda K, Wang N, Schatz G. Requirement for the yeast gene LON in intramitochondrial proteolysis and maintenance of respiration. Science 1994; 264: 237-76.

25 Baba M, Takeshige K, Baba N, Ohsumi Y. Ultrastructural analysis of autophagic process in yeast: detection of 1994; 124: 903-13

26 Berg R, Bernsconi P, Fowler D, Cautreaux M. Inhibition of Candida albicans translocation from the gastrointestinal tract of mice by oral administration of Saccharomyces boulardii. F Infect Dis 1993; 168: 1314-8.

27 Le Fevre ME, Olivio R, Vanderhoff JW, Joel DD. Accumulation of latex in Peyer's patches and its subsequent appearance in villi and mesenteric lymph nodes. Proc Soc Exp Biol Med 1978; 159: 298-302.

28 Hodges GM, Carr EA, Hazzard RA, Carr KE. Uptake and translocation of microparticles in the small intestine: morphology and quantification of particle distribution. Dig Dis Sci 1995; 40: 967-75.
29 Wells CL, Maddaus MA, Erlansen SL, Simmons RL. Evidence for the phagocytic transport of intestinal particles in dogs and rats. Infect Immun 1988; 56: 278-82.

30 Madara JL. Pathobiology of the intestinal epithelial barrier. Am $\mathcal{F}$ Pathol 1990; 137: 1273-81.

31 Rehnberg GL, Hein JF, Carter SD, Laskey JW. Age-dependent changes in gastrointestinal transport and retention of particulate manganese oxide in the rat 7 Toxicol Environ Health 1985; 16: 887-99.

32 Lefevre ME, Boccio AM, Joel DD. Intestinal uptake of fluorescent microspheres in young and aged mice (42825). Proc Soc Exper Biol 1989; 190: 23-7.

33 Eldridge JH, Hammond CJ, Meulbroek JA, Staas JK, Gilley RM, Tice TR. Control vaccine release in the gut-associated lymphoid tissues. 1. Orally administered biodegradable microspheres target in the Peyer's patches. Fournal of Controlled Release 1990; 11: 205-14.

34 O'Hagan DT, Rahman D, Jeffery H, Sharif S, Challacombe SJ. Controlled release microparticles for oral immunization. Int f Pharmacol 1994; 108: 133-9.

35 Dilova V, Shishkova V. Albumin microspheres as a drug delivery system for dexamethasone: pharmaceutical and pharmacokinetic aspects. $\mathcal{f}$ Pharm Pharmacol 1993; 45: pharmaco. 